\title{
Hermenêutica simbólica, Jung e transdiciplinariedade: luzes e sombras na educação
}

\author{
Silvia A. O. C. Martinez* (1) \\ Amauri C. Ferreira
}

Pontifícia Universidade Católica de Minas Gerais, Belo Horizonte, MG, Brasil

\begin{abstract}
Resumo: Este artigo de revisão e análise narrativa de literatura parte da perspectiva transdisciplinar com o objetivo de buscar alternativas epistêmico-metodológicas para que as pesquisas em educação desloquem-se da mera aquisição de conhecimentos à possibilidade de ampliação da consciência. O percurso narrativo do trabalho transita pelas interfaces dialógicas entre os pressupostos da transdisciplinariedade e os da hermenêutica simbólica do círculo de Eranos (HSCE). De forma inédita, alcança o objetivo no uso do conceito de unus mundus (Carl Gustav Jung) como ferramenta simbólica do fazer hermenêutico de transformação da realidade. No processo, via circularidade hermenêutica, múltiplas interfaces emergem a cada instância percorrida nas polaridades de luz e sombra, entre teorias e biografias.
\end{abstract}

Palavras-chave: transdisciplinaridade, hermenêutica simbólica, unus mundus, interfaces na educação.

\section{Introdução}

O presente artigo de revisão de literatura é a primeira comunicação da tese de doutorado cujo trajeto narrativo buscou alternativas epistêmicometodológicas às pesquisas no campo. $\mathrm{O}$ trabalho apresenta, resumidamente, a forma alcançada na tese para ultrapassar fronteiras do conhecimento, pontuando interfaces obtidas através de amplos percursos e profundos mergulhos narrativos que não podem ser reproduzidos neste curto espaço. Buscar e apresentar alternativas epistêmico-metodológicas às pesquisas em educação, a partir da composição de interfaces transdisciplinares, não é uma tarefa fácil. No desafio, os autores ultrapassam fronteiras dos conhecimentos em seu percurso através das interfaces entre os pressupostos da transdisciplinaridade e os da hermenêutica simbólica do círculo de Eranos (HSCE). Assim, a transdisciplinariedade assume os sentidos da origem latina de seu prefixo trans, de trânsito, movimento para além de $^{1}$, que supera a interdisciplinaridade como etapa superior, conforme diz Piaget:

Enfim, na etapa das relações interdisciplinares, pode-se esperar ver suceder uma etapa superior que seria transdisciplinar, a qual não se contentaria em atingir as interações ou reciprocidades entre as pesquisas especializadas, mas situaria essas ligações no interior de um sistema total, sem

\footnotetext{
Endereço para correspondência: silviamartinezop@yahoo.com.br

1 Trans. (n.d.). In Dicionário Aurélio online. Recuperado de https:// bit.ly/366i6Zf
}

fronteiras estáveis entre as disciplinas. (Alvarenga, Philippi Júnior, Sommerman, Alvarez, \& Fernandez, 2011, p. 37). união ao unus mundus extratemporal. (Jung, 2012d)

Em interface, Penna (2013) esclarece que Jung afasta-se dos paradigmas vigentes em sua época pela perspectiva simbólico-arquetípica da realidade (reinserção metafísica) que integra aspectos dissociados pela unilateralidade e linearidade racionais como: subjetividade/objetividade, razão/espírito, individual/ coletivo, pessoal/universal.

Segundo Rizek (2000), Jung também inclui em seus estudos aspectos da cultura como religião, alquimia, mitologia e astrologia como fenômenos de ampliação psíquica da visão da ciência (consciência).

Importante observar, como interface, a conformidade dessa tendência de Jung, com a perspectiva consensual dos integrantes do círculo de Eranos, conforme descrito por Andrés Ortiz-Osés (2012)2:

Eranos encarna a mediação do irracional e o racional, de inconsciente e consciência, mito e logos. Seu projecto radical é fundar um mundo - UNUS MUNDUS - através de relações e do relacionismo como fio condutor. (Ortiz-Osés, 2012, p. 29)

Homem e mundo são tomados em sua totalidade como paralelo metafísico, sob o princípio da analogia e os pressupostos da hermenêutica, em que cada aspecto

2 Andrés Ortiz-Osés. (2020, 29 de junho). In Wikipedia. Recuperado de https://bit.ly/2IEoX3S 
da existência está intimamente ligado aos demais. Unus mundus é uma cosmovisão que não se encerra na explicação das causas, mas ressalta as relações na totalidade cósmica onde o ser humano está inserido (Penna, 2013).

A noção de totalidade está expressa nas mandalas, correlatos simbólicos ao unus mundus e à sincronicidade, que representam sistemas de relações em que a totalidade integra todas as polarizações: entre o consciente e o inconsciente, a psique e o corpo etc. Esses sistemas implicam em relações multivetoriais em que as partes se entrelaçam e interagem, em processos de diferenciação e integração constantes, rumo à complexidade crescente.

Abarcam tanto relações causais, contidas na dimensão espaço-tempo, quanto acausais, fundadas na dimensão simbólica, por associação de significado (sincronicidade). O simbólico seria, então, a ponte epistemológica entre o mundo material e imaterial, entre o objetivo e o subjetivo. No mundo como ambiente em torno do indivíduo, a realidade fenomenológica vivenciada (tempo, espaço, história e cultura) é designada por Jung como consciência coletiva. "Mundo" refere-se ao inconsciente como ambiente interno, no qual se incluem imagens e sonhos, na esfera pessoal, e arquétipos, na esfera coletiva. Dessa maneira, mundo interno e externo, psicologicamente, não se distinguem; ambos são percebidos e vividos na experiência psicológica, de forma simbólica e complementar (Penna, 2013).

Se para o ego mundo externo e interno são vividos como não-eu, a noção de unus mundus abarca relações entre ontogênse/filogênese, macrocosmo/microcosmo, inconsciente/consciente e individualidade/coletividade, formando um todo dinâmico. A dinâmica é estabelecida na correspondência que se opera na tensão/conciliação das polaridades, o que tende ao equilíbrio, segundo as leis da física que estão exatamente nos princípios de autorregulação da psique (Penna, 2013).

o ser humano não nasceu tábula rasa, apenas nasceu inconsciente; trazendo consigo sistemas organizados e padrões que estão prontos a funcionar numa forma perfeitamente humana ... Denominei este modelo instintivo, congênito e preexistente de arquétipo. Esta é a imagem carregada com o dinamismo que não podemos atribuir a um ser humano individual. (Jung, 2012c)

Ortiz-Osés observa que hermeneutizar é revelar o mito sob os conceitos, o que não significa "desmitologizar", pois mitos, arquétipos, crenças e ilusões são condensações de energia psíquica libidinal (Ortiz-Osés, 2004).

Jung dedicou um volume de suas Obras Coletadas ao tema energia psíquica libidinal que chamou: A Energia Psíquica (Jung, 2012a). Nessa obra, fruto de sua parceria de duas décadas com o Nobel da física Wolfgang Pauli, Jung considera a física quântica na elaboração de sua delimitação conceitual de energia psíquica e considerou os arquétipos responsáveis pela organização dos processos psíquicos inconscientes. Com carga de energia psíquica específica, os arquétipos desenvolvem efeitos numinosos expressos em afetos que produzem alterações do nível de consciência, ou abaissement de niveau mental ${ }^{3}$. Essas alterações resultam em períodos de desorientação que oferecem oportunidades aos conteúdos do inconsciente emergirem para a consciência. Para Jung, o médico atento, ao se deparar com esse tipo de evento, poderá identificar “. . . o aparecimento de paralelos simbólicos que não podem ser explicados satisfatoriamente sem a hipótese do inconsciente coletivo" (Jung, 2012e).

Jung revoluciona a ciência com a publicação do que se tornaria o volume 8/3 da coleção Obra Completa, da editora Vozes, e o texto Sincronicidade, um princípio de conexões acausais. Nessa obra, também resultado de sua parceria com Pauli, Jung ao estabelecer conexões entre a física quântica e a psicologia analítica, delinea uma interface ainda pouco explorada. Outras interfaces teóricas e biográficas emergem como pistas em diversas outras fontes citadas em seus textos. Por exemplo, a noção de que o ponto de vista energético geral é aplicável à psique emerge do seu diálogo com Wundt e resulta do entendimento da psique como um sistema energético fechado. Já da sua aproximação a Von Grot, deriva a noção de que o conceito de energia psíquica é tão legítimo quanto o conceito de energia na física, sendo a energia psíquica igualmente explicada pelas mesmas leis gerais de energia da física.

Nesse processo de construção do conhecimento, a aproximação e conformação de interfaces entre saberes contradiz a crença de que a psique seja uma espécie de secreção do cérebro que é substituída pela noção de epifenômeno (Jung, 2012a) para ser abandonada pouco depois. A par das avaliações quantitativas da energia psíquica, Jung analisa o refinado sistema de avaliações qualitativas da psique como valores psicológicos que importam a um sistema objetivo de valores morais e estéticos coletivos estabelecidos universamente. $\mathrm{O}$ autor interessa-se pelas diferenças de gradiente entre as avaliações subjetivas, sob cuja força relativa é possível reconhecer intensidades de valor desiguais e que valores iguais, nas mesmas condições, equilibram-se (Jung, 2012a).

Para Jung a energia psíquica é observada em suas manifestações como: instintos, desejos, vontades, afetos, atenção, rendimento e trabalho, abarcando também processos inconscientes. Jung estabelece o conceito de energia em bases profundas e em amplas interfaces, chegando a incluir nesse processo de delimitação a hipótese filosófica da alma universal, algo que reforça seu diálogo com os pressupostos mediatizadores da transdisciplinariedade e da HSCE. A energia psíquica, compreendida como força vital e especificação da energia universal, é então designada por Jung como libido. Atento à repercussão de suas publicações, Jung observou

3 Abaissement de niveau mental: rebaixamento de nível mental, no sentido de alteração de nível de consciência. 
que seus opositores “. . . não conseguiram demonstrar com segurança a separação dos processos psíquicos dos físicos" (Jung, 2012b).

No interesse do debate com a educação, sobre sua lógica de limitação da consciência à racionalidade em detrimento das demais funções da psique, já sabemos que Jung atribuiu à libido, em bases experimentais, as mesmas leis gerais de conservação de energia da física, como o princípio da equivalência e os fatores de intensidade e extensidade, que determinam que uma atividade psíquica só pode ser substituída por outra equivalente. Percebendo que, no ponto de vista energético, a substância expressa um sistema de energia e, portanto, um determinado modo de ver as coisas é correspondente a atitudes psicológicas (Jung, 2012a). Sendo o que é um fato para o modo causal de observação, é símbolo para o modo finalista e, viceversa, do que decorre que "a realidade é um fenômeno psíquico ... e a ciência não pode ignorar as condições psicológicas do conhecimento" (Jung, 2012b).

Como resultado, temos que quanto maior a tensão entre os opostos, maior a energia produzida e maior a força de atração constelada na busca do equilíbrio estável. O equilíbrio é obtido após fortes oscilações iniciais determinadas no percurso pendular entre os extremos, da unilateralidade à compensação. Esse movimento de percorrer as instâncias entre os extremos termina por produzir uma atitude estável. O princípio da entropia é complementar ao princípio da equivalência. A clínica comprova que a superação de graves conflitos deixa segurança e tranquilidade difíceis de perturbar ou rupturas difíceis de curar (Jung, 2012b).

Em interface, para o físico Nicolescu, a descoberta da escala quântica de realidade, cujas leis são absolutamente diferentes da realidade visível cotidiana, foi a mais importante contribuição da física moderna para a emergência das noções de níveis de realidade, o que resultou em uma nova visão de mundo. Contribuiu com a epistemologia da complexidade, em sua concepção simbólica de realidade, de interação e de participação. No interesse maior do debate com a educação, estabeleceu interfaces ao pressuposto junguiano de que toda realidade é psíquica. Para Nicolescu, a realidade, como percepção, não existe por si mesma. Minimamente, a humanidade intervém na realidade por seus processos de medição e interpretação. Concebe entre a escala das partículas e a escala dos planetas, ou seja, entre os níveis de realidade, que a humanidade se configura no plano ontológico como um sistema de interfaces (Nicolescu, 1995, p. 142).

A tradução de um nível de realidade para outro depende da compreensão da natureza da complexidade concebida de forma contextual por Morin como epistemologia da complexidade: "No início era a complexidade" (Nicolescu, 1995, p. 139). Também participante do Manifesto da Transdiscipinariedade, Morin (2007) estabelece com seu pensamento uma interface da transdisciplinariedade à proposta da construção de conhecimento do círculo de Eranos em texto-contexto-intertexto:

O conhecimento pertinente é o que é capaz de situar qualquer informação em seu contexto $e$, possível, no conjunto em que está inscrito. Podemos dizer que o conhecimento progride, não tanto por sofisticação, formalização e abstração, mas, principalmente, pela capacidade de contextualizar e englobar. (Morin, 2007, p. 15-16)

Nesse sentido, em sua análise sobre a cosmologia de Jacob Boehme ${ }^{4}$, de forma análoga às propostas da transdisciplinariedade e da hermenêutica simbólica, a mediação dos opostos na natureza implica na ultrapassagem da ilusão de um único nível de realidade dado pelos órgãos dos sentidos e pelos instrumentos de medição que os prolongam. Da aproximação entre planos de realidade e entre contradições, resulta a abolição da linearidade e da singularidade do pensamento racionalista e positivista.

Surge, então, a realidade plural das lógicas, das linguagens, das causalidades, das complexidades, dos diversos níveis de realidades e dos diversos tipos de conhecimentos. Se levadas à educação, tornam-se possibilidades consideráveis de exercícios de tolerância humanizantes. Além das implicações éticas, pode-se considerar, por outro lado, as limitações do determinismo mecanicista, no positivismo e no niilismo, como frustrantes no enfrentamento de desafios complexos. Mesmo que percebida e apropriada no campo da racionalidade, a transdiciplinariedade permite o diálogo entre racional-irracional, sagrado-profano, simplicidadecomplexidade, unidade-diversidade, natureza-imaginário, homem-universo.

Antigo símbolo da grande obra alquímica, o ouroboros, a serpente que come a própria cauda, seria uma imagem hermenêutica capaz de expressar a composição de interfaces em sua dinâmica de interação e transformação (Nicolescu, 1995).

\section{Considerações finais}

$\mathrm{O}$ artigo, em seu percurso narrativo, transita entre planos de realidade e níveis de consciência, estabelecendo paralelos, sobrepondo e transpondo noções, evitando mutilar a complexidade da realidade. Mergulhando ocasionalmente em certos aspectos das teorias, deixa escapar alguns detalhes enquanto persegue outros como pistas que em texto-contexto-intertexto, poderiam inclusive ser oriundas de biografias. A composição de interfaces atende e/ou provoca, de forma lúdica, curiosidades científicas em diversas direções e múltiplos sentidos, mantendo tensões e provocando reflexões e debates.

O aporte da noção de consciência ampliada, dotada de energia psíquica libidinal, movendo as

4 Um sapateiro discípulo de Paracelso. 
ações humanas, inscrito no cerne do conceito de unus mundus, permite que múltiplos sentidos se entrelacem nas interfaces, segundo os pressupostos da HSCE e da transdisciplinariedade; sugerindo revisões críticas e propondo alternativas criativas às posturas linearizantes, de aprisionamento a métodos de pesquisa e de análise fixados, nos habitus ${ }^{5}$, entre fronteiras do conhecimento.

Essa abordagem apresenta a hermenêutica simbólica como um processo de livre interpretação que abre possibilidades de conhecimentos que atravessam as disciplinas, buscando contribuir com a construção de maior atitude crítica e discernimento criativo em ambientes compiladores.
A elaboração de interfaces dialógicas adere à proposta da construção da postura transdisciplinar (transnacional, transcultural e transreligiosa) que abarca, sem distinções, múltiplos saberes, incluindo os não científicos, tendo como meta uma cultura de paz, capaz de lidar com tensões que ameaçam a vida de nosso planeta. O conceito de unus mundus, ferramenta simbólica acolhida na aproximação entre física quântica, psicologia analítica, postura transdisciplinar e HSCE, permite-nos ultrapassar, oitava acima, os limites estabelecidos pelas disciplinas - conformando ampla interface entre áreas do conhecimento e estabelecendo pontes dialógicas que convidam ao prazer das descobertas encorajando novas abordagens.

\section{Hermenéutica simbólica, Jung y transdisciplinariedad: luces y sombras en la educación}

Resumen: Este artículo de revisión y análisis narrativo de la literatura parte de una perspectiva transdisciplinar con el objetivo de buscar alternativas epistémico-metodológicas para que la investigación en educación pase de la mera adquisición de conocimientos a la posibilidad de expansión de la conciencia. El texto establece interfaces dialógicas entre los supuestos de la transdisciplinariedad y los de la hermenéutica simbólica del círculo de Eranos (HSCE). Se alcanza la meta de manera inédita con el uso del concepto de unus mundus (Carl Gustav Jung) como herramienta simbólica del hacer hermenéutico de transformación de la realidad. En el proceso, por medio de la circularidad hermenéutica, emergen múltiples interfaces en cada instancia recorrida por las polaridades de luz y sombra, entre teorías y biografías.

Palabras clave: transdisciplinariedad, hermenéutica simbólica, unus mundus, interfaces en la educación.

\section{Symbolic hermeneutics, Jung and multidisciplinarity: light and dark in education}

Abstract: This review and narrative analysis of the literature adopts a multidisciplinary approach to seek epistemological-methodological approaches for research in education to switch from mere knowledge spreading into a potential increase in consciousness. This paper follows the dialogical interface between multidisciplinarity and the symbolic hermeneutics of the Eranos circle (HSCE). It utilizes the concept of unus mundus by Carl Gustav Jung as a symbolic tool of hermeneutic work that transforms reality. By this hermeneutic circularity process, multiple interfaces emerge for every step in analyzing theories and biographies, following a dichotomy of light and dark.

Keywords: multidisciplinarity, symbolic hermeneutics, unus mundus, interfaces in education.

\section{Herméneutique symbolique, Jung et transdisciplinarité : d'ombres et de lumières dans l'éducation}

Résumé: Cet article de synthèse et analyse narrative littéraire s'appui sur la perspective transdisciplinaire pour trouver des alternatives épistémico-méthodologiques pour que la recherche en éducation passe de la simple acquisition de connaissances à l'extension de la conscience. Notre parcours narratif passe par les interfaces dialogiques entre les postulats de la transdisciplinarité et de l'herméneutique symbolique du Cercle d'Eranos (HSCE). D'une manière sans précèdent, on trouve utiliser le concept d'unus mundus (Carl Gustav Jung) comme un outil symbolique pour la transformation herméneutique de la réalité. Ce faisant, par circularité herméneutique, plusieurs interfaces émergent à chaque sphère parcourue dans la polarité de l'ombre et de la lumière, entre théorie et biographie.

Mots-clés: transdisciplinarité , herméneutique symbolique , unus mundus, interfaces dans l'éducation.

5 Para Pierre Bourdieu, habitus indica disposição incorporada, perspectiva que disciplina os comportamentos de que derivam campos estruturados e estruturantes (Bourdieu, 2005, p. 61). 


\section{Referências}

Andrés Ortiz-Osés. (2020). In Wikipedia. Recuperado de https://bit.ly/32hhbnT

Alvarenga, A. T. de, Philippi Júnior, A., Sommerman, A., Alvarez, A. M. de S., \& Fernandes, V. (2011). Histórico, fundamentos filosóficos e teórico-metodológicos da interdisciplinaridade. In A. Philippi Júnior, A. J. Silva Neto (Orgs.), Interdisciplinaridade em ciência, tecnologia \& inovação (pp. 3-67). Barueri, SP: Manole.

Boroson, M. (2011). One-moment meditation: "How to meditate in a moment" [Vídeo]. Youtube. Recuperado de https://bit.ly/3k32B9r

Bourdieu, P. (2005) A economia das trocas simbólicas (6a ed.). São Paulo, SP: Perspectiva.

Capes. Encontro acadêmico internacional interdisciplinariedade e transdisciplinariedade no ensino e extensão em educação, ambiente e saúde. Recuperado de https://bit.ly/3euktsu

Castro, M. A. de. (1994). Tempos de metamorfose. Rio de Janeiro, RJ: Editora Tempo Brasileiro.

Ferreira, A. C. \& Silveira, L. H. L. (2015). Do círculo de Eranos à construção do simbólico em Carl Gustav Jung. Psicologia USP, 26(2), 259-268. doi: 10.1590/0103656420140002.

Jung, C. G. (2012a). A Natureza da psique (Obra Completa, vol. 8/2). Petrópolis, RJ: Vozes.

Jung, C. G. (2012b). Energia psíquica (Obra Completa, vol. 8/1). Petrópolis, RJ: Vozes.
Jung, C. G. (2012c). Freud e a psicanálise (Obra Completa, vol. 4). Petrópolis, RJ: Vozes.

Jung,C.G.(2012d). Mysterium Coniunctionis (ObraCompleta, vol. 14/2). Petrópolis, RJ: Vozes.

Jung, C. G. (2012e). Sincronicidade (Obra Completa, vol. 8/3). Petrópolis, RJ: Vozes.

Morin, E. (2007). Introdução ao pensamento complexo (3a ed.). Porto Alegre, RS: Sulina.

Nicolescu, B. (1995). Ciência sentido e evolução: A cosmologia de Jacob Boehme. São Paulo, SP: Attar Editorial.

Ortiz-Osés, A. (2012). Hermenéutica de Eranos: As estruturas simbólicas del mundo. Barcelona: Anhropos Editorial.

Penna, E. M. D. (2013). Epistemologia e método na obra de C.G. Jung. São Paulo, SP: Educ; Fapesp.

Rizek, R. (2000). Prefácio. In: M. F. dos Santos, Pitágoras e o tema do número. São Paulo, SP: Ibrasa.

Rizek, R. (1998). Teoria da harmonia em Platão. Letras Clássicas, (2), p. 251-299. doi: 10.11606/issn.23583150.v0i2p251-299

Recebido: $25 / 01 / 2019$

Revisado: 20/11/2019

Aprovado: 22/10/2020 